Www.jmscr.igmpublication.org

Impact Factor (SJIF): 6.379

Index Copernicus Value: 79.54

ISSN (e)-2347-176x ISSN (p) 2455-0450

crossrefDOI: https://dx.doi.org/10.18535/jmscr/v6i11.43

Journal Of Medical Science And Clinical Research

IGM Publication

An Official Publication of IGM Publication

\title{
Role of computerized tomography scan in identifying non-neoplastic cause of seizure disorders in children
}

Authors

\section{Dr Anindya Sasmal ${ }^{1}$, Dr Sheela Kandulna (Goswami) ${ }^{2}$, Dr Kausik Goswami ${ }^{3}$ \\ Dr Tapan Dhibar ${ }^{4}$, Dr Swati Chakravarti ${ }^{5}$, Dr Gautam Ganguly ${ }^{6}$}

${ }^{1}$ Assistant Professor, Department of Radiodiagnosis, ICARE Institute of Medical Sciences and Research, Banbishnupur, Purba Medinipur, Haldia, West Bengal 721645

${ }^{2,3}$ Assistant Professor, Department of Pediatrics, ICARE Institute of Medical Sciences and Research,

Banbishnupur, Purba Medinipur, Haldia, West Bengal 721645

${ }^{4}$ Professor, Department of Radiology, Bangur Institute of Neurosciences, IPGMER, 52/1A, Sambhunath

Pandit St, Bhowanipore, Kolkata, West Bengal 700025

${ }^{5}$ Professor, Department of Pediatrics, IPGMER, 244, A.J.C. Bose Road, Bhowanipore, Kolkata, West Bengal 700020

${ }^{6}$ Professor, Department of Neuro Medicine, Bangur Institute of Neurosciences, IPGMER, 52/1A, Sambhunath Pandit St, Bhowanipore, Kolkata, West Bengal 700025

Corresponding Author

Dr Sheela Kandulna (Goswami)

Email: dr.sgoswami2010@gmail.com, Mobile: 9434236304

\begin{abstract}
Background: Seizures are an important cause of morbidity and mortality in childhood. It is therefore important to establish accurate diagnosis of seizures and its aetiologies to appropriately manage such patients. Neuroimaging can help to determine whether a seizure in a patient results from a structural abnormality of the brain or its surroundings. It is useful in a variety of clinical settings. The present study was undertaken to find the role of computed tomography $(C T)$ scan in identifying non-neoplastic cause of seizure disorders in children.

Materials \& Methods: It was a hospital based cross sectional observational study. Age, sex, characterization of seizure including onset, time of attack, provocative factors, first attack, total no of attacks, frequency of attack, status of consciousness, prodrome, aura, cerebellar symptoms, duration, post ictal phenomenon, history of drug intake, control of attack by drugs, family h/o of seizure, birth history were noted.

Results: In the present study $34.5 \%$ of children belong to 6-9 yrs age group followed by $27.6 \%$ of $16-18$ yrs group. Most common type of seizure was generalised tonic clonic seizures (29.31\%) followed by complex partial (25.86\%), simple partial (17.24\%) and unclassified/epilepsy syndromes (13.79\%).About 46.55\% of cases CT for detection of lesions were useful in our study.

Conclusion: Though the MRI is more specific in detecting certain focal anomalies its expense and nonavailability make CT scan an adequate initial screening procedure. Thus every child with a seizure should be subjected to a CT scan to determine the underlying aetiology and offer specific treatment.

Keywords: Seizure disorders, Non-neoplastic aetiologies, Computerized tomography, Neuroimaging.
\end{abstract}




\section{Introduction}

A seizure disorder broadly termed as epilepsy from the Greek word epilepsia meaning "taking hold of" was first described by Hughling Jackson in $1873 .{ }^{1}$ Epilepsy is the second most common and frequently encountered neurological condition that imposes heavy burden on individuals, families, and also on healthcare systems. This disorder has a social stigma attached to it, and to a young child it may cause long term psychological damage. Therefore it becomes important to arrive at an etiological diagnosis whenever possible to aid specific therapy. Almost $30 \%$ of patients with a seizure disorder are childre ${ }^{2}$ and the seizure type is partial in $23-66 \%$ of children ${ }^{[3-6]}$. With a conservative estimate of $1 \%$ as prevalence of epilepsy, there are more than 12 million persons with epilepsy (PWE) in India, which contributes to nearly one-sixth of the global burden. ${ }^{7}$

A study conducted in Kolkata's urban population showed an annual incidence rate of 27.27 per 100,000 per year. ${ }^{8}$ A rural epilepsy surveillance program from Uttarakhand showed a prevalence rate of two or more unprovoked seizures to be 7.5 per $1000^{9}$ and this is slightly higher than the prevalence rate in Kerala, a state with higher literacy rates and better public health awareness (4.9/1000). ${ }^{10}$ Shah PA et al (2009) study showed that in Kashmir valley prevalence rates of $3.74 / 1000$ in males and 3.13/1000 in females. ${ }^{11}$

Febrile seizures (FS), head injury, positive family history of epilepsy and developmental delay have been found to be the risk factors for epilepsy in Indian studies. ${ }^{12}$ However, there are significant regional variations. Neurocysticercosis is highly endemic in certain areas such as northern India. Southern states report a high prevalence of a specific reflex epilepsy called hot water epilepsy. ${ }^{13}$

Several laboratory studies should routinely be included in the initial diagnostic workup of seizure -complete blood count (CBC), blood chemistries, liver and thyroid function tests, EEG, and, most importantly, an imaging study of the brain, preferably MRI. CT scanning may be the only feasible study in an emergency or for very young children. ${ }^{14}$

Seizure in later childhood and adolescence represents most common epileptic problem in general practice.

\section{Objectives}

1) To identify CNS lesion in patients with seizure whether it matches with seizure semiology.

2) To characterize the lesion and help to plan out whether medical or surgical modalities required

3) To help in diagnostic challenge in pharmacologically refractory cases of seizure such as epilepsy syndromes, temporal lobe epilepsy

4) To determine the varied role of neuroimaging in seizure disorder

\section{Materials \& Methods}

The study was done at the Department of Paediatric Medicine and Paediatric Neurology, IPGMER, the Department of Neuromedicine including the Epilepsy Clinic and Department of Radiology, Bangur Institute of Neurosciences, IPGMER.

\section{Inclusion Criteria}

Patient attending Neuromedicine and Epilepsy clinic, Bangur Institute of Neurosciences, Paediatric OPD including Paediatric Neurology, IPGMER with the following criteria

1) Age 6-18 yrs

2) Male or female

3) $>1$ episode of unprovoked seizure, $24 \mathrm{hrs}$ apart or more, seizures was classified according to International League against Epilepsy (ILAE) criteria ${ }^{15}$

\section{Exclusion Criteria}

1) Patient with seizure disorder, < 6yr or > $18 \mathrm{yrs}$

2) Patient with seizure disorder diagnosed to be due to neoplastic causes from neuroradiological evidences 
Sample Size: 58 cases, male or female of age group 6-18 yrs with clinical presentation of seizure disorder

Study Period: February 2010 — September 2011

Sample Design: All such cases attending Department of Paediatrics including paediatric neurology, IPGMER, Department of Neuromedicine including Epilepsy Clinic, Bangur Institute of Neurosciences

Study design: It was a hospital based cross sectional observational study. Age, sex, characterization of seizure including onset, time of attack , provocative factors, first attack, total no of attacks, frequency of attack, status of consciousness, prodrome, aura, cerebellar symptoms, duration, post ictal phenomenon, history of drug intake, control of attack by drugs, family h/o of seizure, birth history were noted.

Radiological Investigations: CT scan of brain in axial plane before and after contrast administration

Study Tool:

- TOSHIBA made ASTEION 4, 4 slice spiral CT scan machine

- Patient is placed in supine position with head coil (quadrature coil).

\section{Techniques of CT Examination ${ }^{16}$}

CT scans are performed with $15-20^{*}$ angulation to the canthomeatal line (line drawing from the supraorbital ridge to the external auditory meatus). The posterior fossa scanned in, 2-3 $\mathrm{mm}$ thin section to minimize beam hardening artefact and the supratentorial brain above the pyramid with a thicker section of $5 \mathrm{~mm}$. The images are seen from below and consequently are laterally reversed.

\section{Results}

In the present study $34.5 \%$ of children belong to 6-9 yrs age group followed by $27.6 \%$ of $16-18$ yrs group [Table 1]. About 34/58 (58.62\%) were male participants. So, there is definite male predilection in our study.
Table 1: Age group and sex distribution among study participants $(\mathrm{n}=58)$

\begin{tabular}{|l|c|c|c|c|}
\hline $\begin{array}{l}\text { Age Group } \\
\text { (Yrs) }\end{array}$ & Male & Percentage & Female & Percentage \\
\hline $6-9$ & 9 & $15.52 \%$ & 11 & $18.96 \%$ \\
\hline $10-12$ & 12 & $20.69 \%$ & 1 & $1.72 \%$ \\
\hline $13-15$ & 4 & $6.89 \%$ & 5 & $8.62 \%$ \\
\hline $16-18$ & 9 & $15.52 \%$ & 7 & $12.07 \%$ \\
\hline
\end{tabular}

Table 2: Age distribution $(\mathrm{n}=58)$

\begin{tabular}{|l|c|c|}
\hline Age Group (Yrs) & No. of Patient & Percentage \\
\hline $6-9$ & 20 & 34.48 \\
\hline $10-12$ & 13 & 22.41 \\
\hline $13-15$ & 9 & 15.51 \\
\hline $16-18$ & 16 & 27.58 \\
\hline
\end{tabular}

Table 3: Comparison of CT in diagnostic usefulness

\begin{tabular}{|l|c|c|}
\hline Total no. of patient & CT was useful & Percentage of cases \\
\hline 58 & 27 & $46.55 \%$ \\
\hline
\end{tabular}

So, $46.55 \%$ of cases CT for detection of lesions were useful in our study as depicted in the diagram [Table 3].

Table 4: Different aetiologies of seizure obtained in our study $[\mathrm{N}=58]$

\begin{tabular}{|l|c|c|}
\hline Causes of seizure & No. of patient & Percentage \\
\hline Mesial temporal sclerosis & 10 & $17.24 \%$ \\
\hline $\begin{array}{l}\text { Congenital structural } \\
\text { defect }\end{array}$ & 10 & $17.24 \%$ \\
\hline Infective & 10 & $17.24 \%$ \\
\hline Anoxia & 5 & $8.62 \%$ \\
\hline Normal & 14 & $24.14 \%$ \\
\hline Gliosis & 5 & $8.62 \%$ \\
\hline Miscellaneous causes & 4 & $6.9 \%$ \\
\hline
\end{tabular}

Aetiologies identified through imaging process in the present study were mainly normal $(24.14 \%)$, mesial temporal sclerosis, congenital structural defect and infective (17.24\%) each [Table 4].

Table 5: Seizure Pattern

The presenting seizure was classified into different groups as listed below $(\mathrm{n}=58)$

\begin{tabular}{|l|c|c|}
\hline Types of seizure & $\begin{array}{c}\text { Total no. of } \\
\text { patients }\end{array}$ & Percentage \\
\hline Complex partial & 15 & 25.86 \\
\hline Simple partial & 10 & 17.24 \\
\hline Generalised tonic clonic & 17 & 29.31 \\
\hline Absence with & 3 & 5.17 \\
\hline Myoclonic seizure epilepsy & 2 & 3.45 \\
\hline $\begin{array}{l}\text { Partial } \\
\text { secondary generalization }\end{array}$ & 8 & 5.17 \\
\hline $\begin{array}{l}\text { Unclassified/ } \\
\text { syndromes }\end{array}$ & 13.79 \\
\hline
\end{tabular}


Most common type of seizure was generalised tonic clonic seizures $(29.31 \%)$ followed by complex partial (25.86\%), simple partial $(17.24 \%)$ and unclassified/ epilepsy syndromes (13.79\%) [Table 5].

Table 6: CT used in diagnosing different aetiologies $(n=44)$

\begin{tabular}{|l|c|c|}
\hline Causes & $\begin{array}{c}\text { No. of patient } \\
\text { diagnosed by CT }\end{array}$ & Percentage \\
\hline Infective & 6 & 13.64 \\
\hline $\begin{array}{l}\text { Mesial temporal } \\
\text { sclerosis }\end{array}$ & 2 & 4.54 \\
\hline $\begin{array}{l}\text { Congenital } \\
\text { structural defect }\end{array}$ & 9 & 20.45 \\
\hline Gliosis & 4 & 9.09 \\
\hline Anoxia/ hypoxia & 4 & 9.09 \\
\hline Miscellaneous & 2 & 4.54 \\
\hline
\end{tabular}

Percentage of abnormalities by CT in diagnosing different aetiologies like infective, mesial temporal sclerosis and congenital structural defect [Table 6] is presented in the above.

Table 7: Congenital aetiologies of seizure $(n=10)$

\begin{tabular}{|l|c|c|}
\hline Causes & No. of cases & Percentage \\
\hline $\begin{array}{l}\text { Dyke Davidoff Mason } \\
\text { syn. }\end{array}$ & 2 & 22.22 \\
\hline Sturge weber syndr. & 1 & 11.11 \\
\hline Chiari I malformation & 1 & 11.11 \\
\hline Septo-optic dysplasia & 1 & 11.11 \\
\hline Corpus callosum agenesis & 1 & 11.11 \\
\hline Pachygyria & 1 & 11.11 \\
\hline Arachnoid cyst & 2 & 22.22 \\
\hline Porencephalic cyst & 1 & 11.11 \\
\hline
\end{tabular}

Causes of congenital aetiologies of seizure identified through MRI imaging was mainly Dyke Davidoff Mason syndrome and Arachnoid cyst $(22.22 \%$ each) followed by Sturge weber syndrome (Fig. 2), Chiari-I malformation, septooptic dysplasia (Fig. 1), corpus callosum agenesis (Fig. 3), pachygyria and porencephalic cyst (11.11\% each) [Table 7].

Table 8: Percentage of infective cases presenting as ring enhancing lesion $(n=10)$

\begin{tabular}{|l|c|c|}
\hline $\begin{array}{l}\text { Total no of } \\
\text { cases due } \\
\text { to infective } \\
\text { aetiology }\end{array}$ & $\begin{array}{c}\text { No. of cases } \\
\text { presenting } \\
\text { as ring enhancing } \\
\text { lesion }\end{array}$ & $\begin{array}{c}\text { Percentage of cases } \\
\text { presenting as ring } \\
\text { enhancing lesion }\end{array}$ \\
\hline 10 & 07 & 70 \\
\hline
\end{tabular}

So, majority of cases with infective aetiology presented with ring enhancing lesion in our study [Table 8].
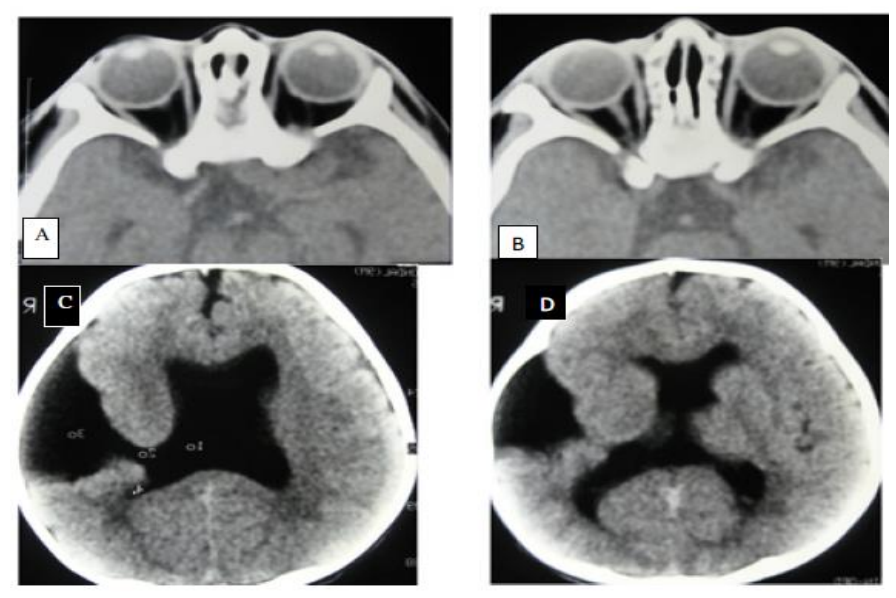

Figure 1: Axial CT images in different Section showing septo-optic dysplasia with right sided type II schizencephaly
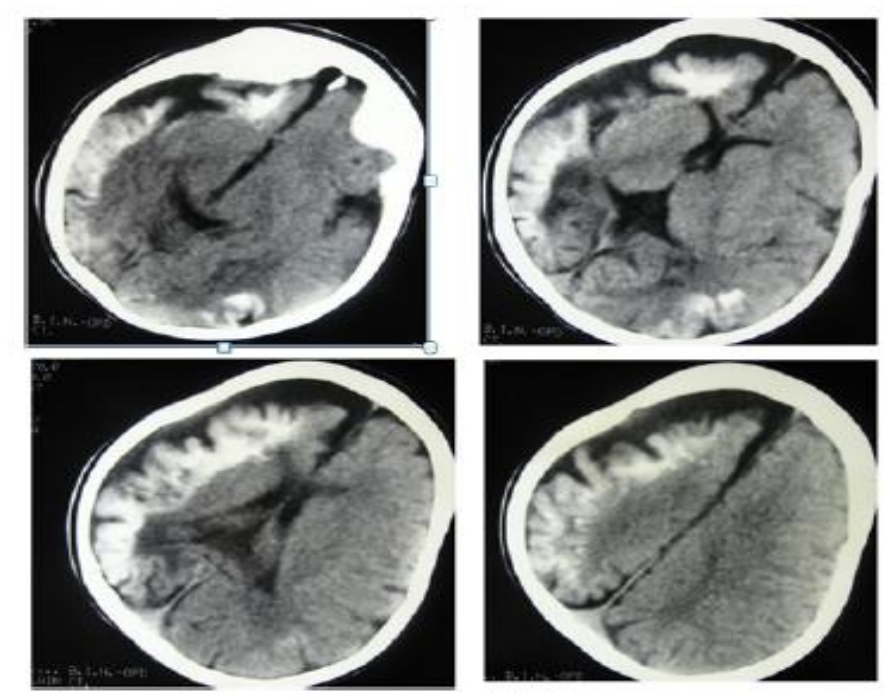

Figure 2: AXIAL noncontrast $\mathrm{CT}$ scan in different sections showing a classical case of Sturge - Weber Syndrome

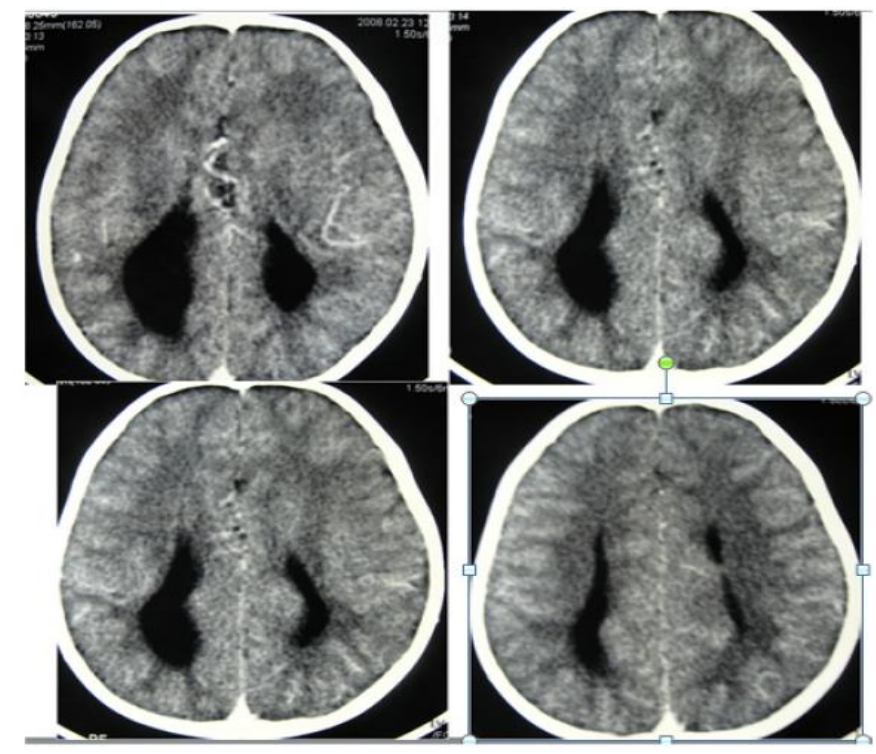

Figure 3: Axial post contrast CT images showing partial agenesis of corpus callosum 


\section{Discussion}

This study was undertaken with a view to determine the role of CT scan in children with a seizure disorder other than neoplastic cause. In our study most of the cases of symptomatic seizure occurred in 6-12 yr age group comprising of almost $56.9 \%$ of all patient. There is also male predilection in our study. Male patient comprises of $58.62 \%$ and female patient comprises of $41.38 \%$ of patients.

The yield of positive results was $46.55 \%$ which is in the range of $30-70 \%$ as quoted by various authors. ${ }^{[3,17,18,19]}$ Maytal J et al (2000) showed that fifty-two patients $(78.8 \%)$ had normal CT results and 14 patients (21.2\%) had abnormal CT results. Seizure cause was considered cryptogenic in 33 patients, of whom $2(6 \%)$ had abnormal CT results; neither patient required intervention. ${ }^{20}$

A cross sectional study by Baheti R et al (2003) based on CT and EEG finding in patients with generalised or partial seizures done in Western Rajasthan in which 52 children of 1-15 yrs age group with seizure disorder were included; 26 of them were having partial seizures, while the rest were having generalised seizures. Those patients who were having known aetiological factors were excluded from the study. All the patients were subjected to a detailed clinical history and physical examination revealed that $57.7 \%$ patient had seizure in 1-10 yr age group and there was definite male dominance among seizure patients. ${ }^{21}$ Partial seizure $(\mathrm{n}=26)$, generalized seizure $(\mathrm{n}=26)$ male for generalized seizure 18 comprises of $(69.2 \%)$, and for partial seizure $19(73.0 \%)$ of patients, where female comprises 08 patient for generalized seizure (30.8\%) and 07 patient $(27.0 \%)$ for partial seizure. On the contrary according to Behavioural aspects of epilepsy: Principles and practice by Steven C. Schachter, Gregory L. Holmes, Dorothée Kasteleijn- Nolst Trenite there has been bias to the female sex in several case series ${ }^{22}$, but this has not been confirmed on controlled study. But most of these studies were based on Western patient. So it can be concluded that there is difference in sex distribution in Western and Indian patients. Comparison of computed tomography (CT) with Magnetic Resonance Imaging (MRI) for intractable epilepsy was done. In a study of 117 patients with intractable epilepsy who had surgically proven abnormalities, MR had a sensitivity of $86 \%$ compared with $28 \%$ by CT. ${ }^{23,24}$ In our study about $46.55 \%$ cases were diagnosed by CT. CT was very poor for particularly detection of mesial temporal sclerosis among 10 patient of mesial temporal sclerosis detected on the basis of MRI, CT was able to detect only 2 cases. In our study CT was useful in detection of congenital structural defect. But according to Bronen RA et al (1996) CT was $15 \%$ sensitive compared to MRI which was $70 \%$ sensitive for detection of congenital lesions. ${ }^{24}$

In diagnostic terms, the CT scan was found to have two enormous advantages. Demonstration of normal structures with ability to diagnose atrophy and demonstration of space occupying lesions, their position and nature to a certain extent, specially solid and cystic masses, tumours, abscesses, haemorrhages and infarctions. ${ }^{3}$ Study by Kanitkar $\mathrm{M}$ et al showed porencephalic cyst or cerebral atrophy was seen in $21 \%$ of abnormal scans and mostly in the preschool children who gave a history of meningitis or birth asphyxia. ${ }^{3}$ In a study conducted by Yang $\mathrm{P}$ et al, 17 out of 34 children with partial seizures had an abnormal CT, the commonest being atrophy. ${ }^{25}$

Electroencephalography (EEG) is recommended as a part of initial evaluation in all children presenting with an episodic event. Epileptiform abnormalities in the EEG support a clinical diagnosis of seizure, help in the diagnosis of specific syndromes, and predict seizure recurrence. ${ }^{26}$ Imaging provides important contributions in establishing etiology, providing prognostic information, and directing treatment in children with recently diagnosed epilepsy. ${ }^{27} \mathrm{~A}$ computed tomography (CT) scan is now widely available with a low marginal cost in private and public sector hospitals. ${ }^{28}$ For neuroimaging, 
magnetic resonance imaging (MRI) is more sensitive than CT and is the modality of choice. ${ }^{29}$ A plain CT scan is indicated in traumatic brain injury and a contrast enhanced CT scan is indicated in children above 2 years, especially those presenting with convulsive seizures, focal seizures, and clusters of seizure. ${ }^{30}$

\section{Conclusion}

Determining whether focal lesion is the cause of seizure also helps in diagnosis of epilepsy syndromes of childhood. Neuroimaging is useful to determine whether early intervention is required or not as in cases of traumatic seizure, vascular aetiologies of seizure. Though CT scan is having radiation exposure risk but single exposure is not having much risk as compared to seizures complications. CT scan brain is an important investigation and should be used in generalized seizures because it is affordable and available at many smaller centers. Limitations of the study include small sample size, and lack of long-term follow-up with repeat CT scan. CT scan can detect many of localized lesions in cases of generalized seizures. CT brain may also be used in cases of generalized seizures, not only in partial seizures especially where the MRI facility is not available and affordable.

\section{References}

1. Binnie CD. Electroencephalography. In: John L, Alan R, Jolyn O, editors. A text book of epilepsy, 3rd Edn. Churchill Livingstone; 1988. pp. 236-237.

2. Pellock JM. The paediatric clinics of North America. WB Saunders; 1989. (Editor). Seizure disorders. IX Vol 36 No 2 (April).

3. Kanitkar M, Purkayastha SB, Deshpande ND. Role of CT scan in partial seizures in children. Med J Armed Forces India. 2017; 50(1):23-26.

4. Cavazzuti GB. Epidemiology of diferent types of epilepsy in school aged children in Medene. Italy, Epilepsia. 1980; 21:5759.
5. Sofijanow NG. Clinical evaluation and prognosis of childhood epilepsies Epilepsia. 1982; 23:61-63.

6. Todt H. The late prognosis of epilepsy in childhood-Results of a prospective follow up study. Epilepsia. 1984; 24:137-139.

7. Amudhan S, Gururaj G, Satishchandra P. Epilepsy in India I: Epidemiology and public health. Ann Indian Acad Neurol. 2015; 18(3):263-77.

8. Banerjee TK, Ray BK, Das SK, Hazra A, Ghosal MK, Chaudhuri A, et al. A longitudinal study of epilepsy in Kolkata, India. Epilepsia. 2010; 51:2384-91.

9. Goel D, Agarwal A, Dhanai JS, Semval VD, Mehrotra V, Saxena V, et al. Comprehensive rural epilepsy surveillance programme in Uttarakhand state of India. Neurol India. 2009; 57:355-6.

10. Radhakrishnan K, Pandian JD, Santhoshkumar T, Thomas SV, Deetha TD, Sarma PS, et al. Prevalence, knowledge, attitude, and practice of epilepsy in Kerala, South India. Epilepsia. 2000; 41:1027-35.

11. Shah PA, Shapoo SF, Koul RK, Khan MA. Prevalence of epilepsy in school-going children (6-18 years) in Kashmir Valley of North-west India. J Indian Med Assoc. 2009; 107:216-8.

12. Bharucha NE. Epidemiology of epilepsy in India. Epilepsia. 2003;44(Supp 1):9-11.

13. Gadgil P, Udani V. Pediatric epilepsy: The Indian experience. J Pediatr Neurosci. 2011;6(Suppl 1):S126-9.

14. Cendes F, Theodore WH, Brinkmann BH, Sulc V, Cascino GD. Neuroimaging of epilepsy. Handb Clin Neurol. 2016; 136:985-1014.

15. Engel International League Against Epilepsy (ILAE). A proposed diagnostic scheme for people with epileptic seizures and with epilepsy: Report of the ILAE task force on classification and terminology. Epilepsia. 2001; 42:796-803. 
16. G D Casino, C R Jack, Neuroimaging in Epilepsy Principal \& Practice, $1^{\text {st }}$ edition, Butterwoth - Heineman, Boston -1996. Matthias Hoffer, CT Imaging manual, 3rd Edition. p -26

17. Bogdanoff BM, Stafford CR, Green L, Gonazales CF. Computerised transaxial tomography in the evaluation of patients with focal epilepsy. Neurology (Minneap) 1975; 25:1013-1017.

18. Bachman DS, Hodges FJ, Freeman JM. Computerised Axial Tomography of the brain in chronic seizure disorders of childhood. Paediatrics. 1976; 58:828-832.

19. Wadia RS, Makhale CN, Kelkar AV, Grant KB. Focal epilepsy in India with special reference to lesions showing ring or disc like enhancement on contrast computed tomography. Journal of Neuro, Neurosurg and Psychiatry. 1987; 50:12931301.

20. Maytal J, Krauss JM, Novak G, Nagelberg J, Patel M. The role of brain computed tomography in evaluating children with new onset of seizures in the emergency department. Epilepsia. $2000 \quad$ Aug; 41(8):950-4.

21. Baheti R, Gupta BD, Baheti R. A Study of $\mathrm{CT}$ and EEG findings in Patients with Generalised or Partial Seizures in Western Rajasthan. JIACM 2003; 4(1): 25-9.

22. Pohlmann-Eden B, Beghi E, Camfield C, Camfield $P$. The first seizure and its management in adults and children. BMJ : British Medical Journal. 2006; 332(7537):339-342.

23. Bronen RA, Fulbright RK, Spencer DD, et al. Refractory epilepsy: comparison of MR imaging, CT, and histopathologic findings in 117 patients. Radiology 1996; 201:97105.
24. Bronen RA, Fulbright RF, Spencer SS, Spencer DD, Kim JH, Lange RC. Comparison of MR and CT imaging of refractory epilepsy: Correlation with postoperative seizure outcome in 109 patients. Int J Neuroradiol 1997; 3:140146.

25. Yang PJ, Berger PE, Cohen ME. Computerised tomography and childhood seizure disorders. Neurology. 1979; 29:1084-1089.

26. Recommendations for neuroimaging of patients with epilepsy. Commission on Neuroimaging of the International League against Epilepsy. Epilepsia. 1997; 38(11):1-2.

27. Gaillard WD, Chiron C, Cross JH, Harvey AS, Kuzniecky R, Hertz-Pannier L, et al. Guidelines for imaging infants and children with recent-onset epilepsy. Epilepsia. 2009; 50(9):2147-53.

28. Kumar R, Kohli N, Thavnani H, Kumar A, Sharma B. Value of CT scan in the diagnosis of meningitis. Indian Pediatr. 1996; 33(6):465-8.

29. Chaudhary, G. and Chaudhary, V. 2017. Evaluation of role of computed tomography scan brain in children with generalized seizures. Indian Journal of Child Health Nov. 2017; 3(1): 36-38.

30. Murthy JM, Yangala R. Acute symptomatic seizures - Incidence and etiological spectrum: A hospital-based study from South India. Seizure. 1999; 8(3):162-5. 